\title{
A POLÍTICA DE EDUCAÇÃO SUPERIOR NO PERÍODO RECENTE - UMA PERSPECTIVA DE ANÁLISE'.
}

\author{
HIGHER EDUCATION POLICY IN THE RECENT PERIOD - AN \\ ANALYTICAL PERSPECTIVE \\ POLÍTICA DE EDUCACIÓN SUPERIOR EN EL PERÍODO RECIENTE \\ -UNA PERSPECTIVA DE ANÁLISIS
}

\section{Arlete Moysés Rodrigues}

Doutora e Livre Docente em Geografia. Professora Associada I no Instituto de Filosofia e Ciências Humanas e no Instituto de Geociências da Unicamp. Rua Paulistania, 520, apto. 11. CEP 05440-001 - São Paulo-SP.

E.mail: moysesarlete@gmail.com

\section{RESUMO}

A política de educação superior tem sido intensamente alterada desde 2016 sem ser devidamente explicitada. O corte elevado de recursos para a ciência e pesquisa e as mudanças nas atividades cotidianas de pesquisadores são demonstrativos de alterações de forma que implicam em mudanças de conteúdo. Do ponto de vista mais geral a aprovação da PEC 55, da Lei n ${ }^{\circ}$. 13.415/2017, que propugna alteração do Ensino Médio, a alteração do regime de partilha no Pré-Sal, a proposta de cobrança de mensalidade para a pós-graduação de universidades públicas e várias outras medidas provisórias implicam na perspectiva de engessar e destruir o pensamento crítico. As alterações atuais, quando comparadas com o PNPG -2011-2020, demonstram que o conteúdo não explícito, está submetido à forma que aprofunda a educação superior como mercadoria.

PALAVRAS CHAVES: Política de Educação Superior, Plano Nacional de Pós-Graduação. PNPG; Pensamento Crítico, Recursos Públicos.

Ideias apresentadas no I Seminário da Pós Graduação em Geografia e Fórum dos Coordenadores de Programas de Pós-Graduação promovido pela Associação Nacional de Pós-Graduação em Geografia (Anpege), realizado na Universidade de São Paulo, na mesa redonda "Políticas para a Educação Superior e Expansão da Pós-Graduação em Geografia" em 28 de março de 2017. 


\begin{abstract}
The higher education policy has been intensely altered since 2016 without being explicit. The high cut of resources for science and research, changes and the daily activities of researchers a demonstrative of changes in form that imply changes in content. From a more general point of view, the approval of PEC 55, and the Law no. 13.415 / 2017, which proposes an alteration of the High School, a change in the system of the Pre-Sal, the proposal of monthly tuition for public universities and several provisional measures implie the perspective of plastering and destroying the critical thinking. The current changes, when compared with the PNPG -2011-2020, demonstrate that the non-explicit content is subjected to the form that deepens higher education as a commodity.
\end{abstract}

KEYWORDS: Higher Educatition Policy, PNPG, Critical Thinking, Resources,

\title{
RESUMEN
}

La política de la educación superior ha sido intensamente alterada desde 2016 sin ser debidamente discutida. El recorte elevado de recursos para ciencia e investigación y los cambios en las actividades cotidianas de investigadores, demuestran que las modificaciones de forma de la enseñanza y la investigación implican en un cambio de contenido. Desde el punto de vista más general la aprobación de la PEC 55, de la Ley $\mathrm{N}^{\circ} 13.415 / 2017$, que altera la educación de la enseñanza media, la modificación de la Ley del Pré-Sal, la propuesta de cobro de mensualidad en los estudios de posgrado en las universidades públicas y de varias medidas provisionales, busca acallar y destruir el pensamiento crítico. Las alteraciones actuales en comparación con el PNPG-20112020, demuestran que el contenido no explícito está sometido a la forma que hace que la.educación sea considerada casa ver más como una mercancía.

PALABRAS CLAVES: Política de La Educación Superior, - PGNP; Pensamiento Crítico, Recursos Públicos. 
A apresentação tem o objetivo de ponderar sobre algumas questões em relação às políticas de educação superior, incluindo elementos sobre expansão da pós-graduação em Geografia.

No atual período, contrapondo-se ao período imediatamente anterior, averiguamos alterações na destinação de recursos públicos direta e indiretamente relacionados à política de educação superior, além, e principalmente, de medidas que limitam os estudos e pesquisas em relação à complexa dinâmica social, econômica e política do Brasil. Vivenciamos um período no qual ciência e pesquisa científica parecem se constituir em "inimigos" do desenvolvimento social, econômico e político. As ações impetradas, aparentemente desconectadas, interferem diretamente na pesquisa científica e impõem novas formas de controle sobre o desenvolvimento e avanço do pensamento.

Assistimos no Brasil o que Mario Benedetti - escritor uruguaio - constatou em seu país, em relação ao desmonte do ensino público:

O sistema é simples. Por exemplo, retiremos fundos da Universidade da República, e quando esta começa a agonizar, e os estudantes, funcionários e docentes saiam às ruas, apontemos então que ineficaz se tornou a educação pública, inclusive a superior, e destaquemos mais uma vez que a solução é a universidade privada, onde não há greves e há até certa facilidade para se formar².

Embora o sistema seja aparentemente simples, a voragem das transformações às vezes impede que tenhamos clareza de sua complexidade.

O ponto de partida para esta apresentação são as premissas do Plano Nacional de Pós Graduação - PNPG - 2011 a 2010 (CNPq. 2011)³, comparando com as implícitas do atual período, que sem serem ditas, estão sendo colocadas em pauta. É sempre complicado fazer comparações, em especial porque o PNPG contém propostas e proposições de conteúdo, enquanto que no período atual as alterações contêm premissas implícitas e estão sendo implementadas com tal velocidade que as transformações são muitas vezes difíceis de captar. Cortam-se recursos, as manifestações das comunidades científicas clamam pelas suas retomadas e assim a falta de recursos, relacionada com despesas e não com investimentos, é justificativa para cobrança de mensalidades dos pós-graduandos e de possíveis privatizações.

O PNPG contem diretrizes de política pública para a pós-graduação. Destaca a ampliação dos cursos nas diversas regiões brasileiras. Com relação à Geografia, em 2014 apenas nos estados do Acre, Amapá e Maranhão não havia programas de pós-graduação em Geografia

2 https://www.brasildefato.com.br/2017/03/23/milhares-de-professores-voltam-as-ruas-em-defesa-da-educacao-publica-naargentina/

3 http://www.capes.gov.br/plano-nacional-de-pos-graduacao. Acesso em março de 2017 
(OLIVEIRA e SANT'ANNA NETO, 2014). Nessa perspectiva, busca-se, com a expansão, melhor distribuir os cursos de pós-graduação nas grandes regiões brasileiras.

O PNPG é uma agenda de política pública que propõe expandir o conhecimento aprofundado de diversas questões sociais, políticas econômicas e tecnológicas nas diversas regiões do país, o que poderia permitir, ainda que não possamos afirmar que isto está ocorrendo em sua plenitude, a constituição de uma Geografia nacional não apenas concentrada nos grandes centros urbanos do sudeste e da faixa litorânea. A expansão da pós-graduação no território nacional poderia permitir análises centradas em especificidades regionais. Fica a indagação se de fato contribuem para entender a totalidade ou se acabam por se centrar em especificidades regionais e locais sem relacionar com a totalidade. Desconheço pesquisas sobre se a implantação de Campus de graduação e de pós-graduação alterou a dinâmica regional e se é possível articular esta expansão com o conhecimento do espaço e do território. Porém, para nós geógrafos, não é novidade que a implantação de um equipamento como uma universidade, ou mesmo sua ampliação, quando existente, muda o uso do solo nas imediações, provocando alterações na dinâmica urbana e aumento do preço da terra e das edificações dentro da lógica de avanço do capitalismo.

De qualquer forma, o processo de expansão dos cursos de geografia e da pós-graduação em várias regiões do Brasil significa maior acesso à universidade pública e aos temas que dizem respeito à sociedade do lugar. A implantação de uma política pública necessita de recursos para ser concretizada e, durante pelo menos uma década, houve liberação de recursos para a expansão da graduação e da pós-graduação bem como de aumento de bolsas da Capes e $\mathrm{CNPq}^{4}$. O aumento de bolsas está relacionado ao aumento do número de estudantes, mas também à compressão do tempo para a realização de mestrados e doutorados.

No PNPG aparece com destaque a relação entre os temas econômicos, sociais e a política para a educação superior. Correlaciona a pesquisa com a necessidade de analisar problemas rurais e urbanos, mudanças climáticas, exploração de riquezas minerais e de fontes de energia entre os quais a exploração do petróleo do Pré-Sal. Ou seja, é uma política pública cujo conteúdo é relacionado com o desenvolvimento econômico e social e a necessidade da ciência e da técnica para sua concretização. Apresenta ponderações importantes para o entendimento dos problemas resultantes da produção e reprodução do espaço rural e urbano.

Averigua-se que no PNPG é ressaltada a importância do avanço da tecnologia como um dos fundamentos da pesquisa e política universitária. O capital não sobrevive sem pesquisa estatal, demonstra Mariana Mazzucato (2014) ao mostrar o recebimento de concessões

a $\quad$ Cf. OLIVEIRA e SANT'ANNA NETO (2014). 
e financiamentos, nos Estados Unidos, para a política tecnológica. Nenhum investidor privado ou força de mercado pode fazer o trabalho de educar e financiar pesquisas visando o desenvolvimento social e econômico. Mas o que nos interessa não é uma avaliação do PNPG e do que se implantou, apesar de ser necessária uma análise crítica sobre as contradições e conflitos decorrentes da expansão.

A política para a educação superior pressupõe, no âmbito do Estado capitalista, uma relação entre o desenvolvimento cientifico, em especial o tecnológico, e o desenvolvimento capitalista. O elo, porém, rompe-se e assim a comunidade científica brasileira programou, juntamente com outras entidades científicas mundiais, manifestação em 22 de abril de 2017 contra os cortes de recursos destinados à política cientifica. A manifestação foi programada em várias partes do mundo, pois não é uma especificidade brasileira a expansão das políticas neoliberais no desenvolvimento da ciência e da tecnologia. Apesar de fundamental para o desenvolvimento econômico, social e político e ser um investimento para o presente e futuro, o neoliberalismo considera a ciência e tecnologia como despesas e não como investimento.

O que estamos, portanto, averiguando na atual conjuntura é a proposta implícita do fim do pensamento crítico e da relação da pós-graduação com o desenvolvimento econômico e social. É como se pensar, pesquisar, raciocinar incluindo aqueles que defendem a importância da pesquisa científica e do pensamento crítico tenham se tornado o inimigo a ser combatido. Só assim podemos compreender a tentativa, que espero não seja concretizada, de acabar com o pensamento crítico.

Há várias formas de combater a pesquisa científica pública e o pensamento crítico, desde cortes nos recursos até, de forma sutil, a implantação de formas de controle ou de aumento do trabalho administrativo/burocratizado que dificulta a pesquisa e o pensamento reflexivo. Alterações que são interiorizadas, naturalizadas como "necessárias" e que significam, no conjunto, alteração profunda da política universitária ${ }^{5}$. Implícita em muitas dessas novas atividades administrativas está a possibilidade de diminuir os funcionários das universidades e a terceirizar as atividades em função de que o professor-pesquisador passa a ser responsável por várias atividades administrativas. A Lei no. 13.429/2017 sobre a terceirização indica um processo de substituição dos funcionários das universidades e no limite do professor-pesquisador.

A perspectiva atual, não explícita, é a de manter o que já existe, sem ampliar a graduação e menos ainda a pós-graduação. Poderia ser a retomada do Tratado de Uti

\footnotetext{
5 - Desde abril de 2017 professores e pesquisadores da Unicamp são responsáveis por preencher via digital toda a documentação referente a exames de qualificação bem como de defesa de Teses e dissertações o que era realizado em conjunto com as secretárias da pós-graduação. Disponível em http://www.dac.unicamp.br/portal/.
} 
possidetis para a universidade pública. Poderia, mas não é. Porque se atua com cortes de recursos, planeja-se cobrar mensalidades de pós-graduandos e, no limite, privatizar. Retiram-se funções de funcionários das universidades para substituí-los por terceirizadas, pagando menos e sem compromisso com o trabalho. Ou seja, cortes de recursos indicam que os novos cursos de pós podem estagnar e até mesmo fechar. Parece que a expectativa é destruir o que existe para justificar a privatização, um sistema de destruição no qual a ciência, os pesquisadores são inimigos a serem destruídos. O ideário da atual política, não explícita, é destruir a potência do pensamento (AGAMBEN, 2008), é destruir a sociedade que será não apenas submissa, mas carente de imaginação para criar alternativas sociais, econômicas e políticas.

O Projeto de Lei 867 de 2015, autodenominado escola sem partido, pressupõe que estudantes devam ser treinados (melhor dizer, adestrados) para decorar nomes, datas, acidentes geográficos, nomes das capitais, fórmulas químicas e matemáticas, sem refletir no significado, ou seja, ocupar as mentes dos jovens com dados para impedir o desenvolvimento do pensamento. Impedir o pensamento crítico por lei é apenas sistematizar o que já ocorre na realidade, pois ao observarmos o atual rumo da sociedade mundial, averiguamos que a influência do pensamento crítico tem sido mínima, senão não estaríamos vivenciando um processo de dilapidação da pesquisa e do ensino. O que mais influencia a vida na atual sociedade do consumo é a mídia acrítica. O que se pretende com o projeto 'escola sem partido’ é apenas oficializar, via projeto educacional explícito, uma doutrinação já dominante na sociedade civil há várias décadas: a ideologia neoliberal.

O neoliberalismo, e todo o seu conjunto de prescrições meritocráticas, individualistas e excludentes, é a verdadeira doutrinação no Brasil. Professores e pós-graduandos devem publicar cada vez mais sem importar o que, desde que seja amplamente divulgado e de preferência publicado em revistas tidas como de alto padrão. Estas formas de medir a "produção" não são novas, porém expandem-se no atual momento tornando-se o centro da atenção e vão sendo cristalizadas como naturais.

Paradoxalmente a expansão dos cursos de pós-graduação ocorre quando já estão estabelecidos critérios estreitos para que estes cursos obtenham notas que podem garantir bolsas para os pósgraduandos. As notas eram atribuídas por "visitas" de representantes da Capes - Coordenação de Aperfeiçoamento de Pessoal de Nível Superior -, para averiguar a infraestrutura e a produção cientifica - artigos, livros de professores e pós-graduandos, teses e dissertações. Recentemente, porém as "visitas" foram suspensas, por economia de recursos. Ao que tudo indica serão consideradas as citações dos livros, artigos que constam do Google acadêmico. Como avaliar a qualidade dos textos? Como avaliar se um texto é utilizado por alunos de graduação considerando 
que a maioria dos alunos de graduação não publica, considerando tratar-se de um processo de formação? Quem entra como citado no Google acadêmico?

O Google acadêmico pode ser, do ponto de vista científico, índice para pontuação? Qual a qualidade deste instrumento? Qual o critério que usa? Qual o objetivo do Google em criar um levantamento sobre citações de um autor? Os seus dados podem ser utilizados para classificar a qualidade de artigos? O Google Acadêmico, segundo sua própria definição, é uma ferramenta de busca que possibilita a pesquisa em artigos revisados por especialistas, teses, livros, resumos e artigos de editoras, organizações profissionais, universidades e outras entidades acadêmicas. Ou seja, uma ferramenta que coleta informações sobre citações pode ser o indicador de avaliação?

Esta ferramenta não pode ser utilizada para avaliar a qualidade e o conteúdo da produção acadêmica. É um índice numérico feito por uma empresa privada. Cabe relembrar que os coordenadores da pós-graduação em Geografia elaboraram nota pública ponderando sobre a necessidade de debater o uso de tal índice. A resposta, por parte dos representantes da área na CAPES, indica a naturalização e aceitação do uso da ferramenta privada sem debate com os programas de pós-graduação sobre o que representa o uso de tal instrumento ${ }^{6}$.

A política para a pós-graduação é alterada no que parece ser apenas forma de coleta de informações, porém no uso de tal ferramenta, está implícita que o que importa não é a qualidade e nem o conteúdo, mas o número de citações. Martin Hilbert, professor da Universidade da Califórnia, afirma que o fluxo de dados entre cidadãos e governantes pode nos levar a uma "ditadura da informação", algo imaginado pelo escritor George Orwell no livro $1984^{7}$. É essa ditadura da informação que está sendo imposta sem o necessário debate crítico. Não se trata apenas da facilidade na coleta de dados, mas de entender o que ela significa. Milton Santos, em várias de suas obras, aponta que utilizar o meio técnico científico informacional para levantamentos científicos pode ser uma armadilha.

A escassez de recursos das universidades para pagamento de viagens com a finalidade de participar de bancas de mestrado e doutorado com debates presenciais faz com que automaticamente se naturalize as arguições via Skype, o que limita o debate científico. O Skipe para apresentações gerais, para debates internacionais - e mesmo considerando a extensão territorial do Brasil - é importante, porém é fundamental pensar no uso indiscriminado de tal tecnologia.

Nem todas as áreas de pós-graduação estão utilizando o Google acadêmico. Afirmo isso por fazer parte de outros dois programas.

http://www.bbc.com/portuguese/geral-39535650?ocid=wsportuguese.chat-apps.in-app-msg.whatsapp.trial.link1_.auin 
Para além das formas que limitam internamente o debate crítico há questões relevantes que demonstram as formas implícitas de alteração na política para a educação superior. Em 24 de março de 2017, em audiência com os dirigentes da PROIFES (Federação de Sindicatos de Professoras e Professores das Instituições Federais de Ensino Superior e de Ensino Básico Técnico e Tecnológico), a secretária executiva do MEC - Ministério de Educação e Cultura, Maria Helena Guimarães de Castro defendeu veementemente a cobrança de mensalidades nas universidades e institutos federais. A cobrança esteve em pauta no governo do PSDB (1995-2002), ficou fora de pauta porque havia política de expansão com desenvolvimento econômico relacionado com o social e contava com recursos do REUNI - Reestruturação e expansão das Universidades Federais. É evidente que com política econômica, vinculada à política pública é possível resolver, não a crise financeira global, mas permitir o desenvolvimento social. (PROIFES, 2017) ${ }^{8}$. O que fica evidente é que hoje há uma política de aprofundamento da educação superior como mercadoria, retirando assim da classe trabalhadora de baixos e médios rendimentos a possibilidade de aprofundar seus conhecimentos.

Felizmente o Projeto de Emenda Constitucional-, PEC 395/14, do deputado Alex Canziani (PTB-PR), que permitiria às universidades públicas cobrarem pela pósgraduação lato senso, exceto mestrado profissional, foi derrotada. Mas só o fato de ser uma proposta de emenda constitucional demonstra como se almeja que a política da educação superior seja, cada vez mais, mercadoria. A PEC propunha pagamento apenas para a pósgraduação lato senso, ou seja, a que se preocupa com a formação científica, enquanto que a voltada para o "mercado" seria isenta do pagamento. O mercado teria primazia já que o mestrado e o doutorado profissional se destinam diretamente a ele. A justificativa era que assim se reforçaria o caixa das universidades, permitindo que elas ofertassem cursos direcionados às empresas. Fica evidente que a pesquisa científica precisa ser "extirpada" para que o pensamento único, ou melhor, o adestramento, seja concretizado e desse modo se caminhar a passos largos para a privatização do ensino superior.

A Portaria n ${ }^{\circ} 389$, de 23 de março de 2017 do MEC institui, no âmbito da pós-graduação estrito senso, as modalidades de mestrado e doutorado profissional. A de mestrado existe desde a década de 90 e o de doutorado será iniciado agora com o objetivo:

de capacitar profissionais qualificados para o exercício da prática profissional avançada e transformadora de procedimentos, visando atender demandas sociais, organizacionais ou profissionais e do mercado de trabalho; de transferir conhecimento para a sociedade, atendendo demandas específicas e de arranjos produtivos com vistas ao desenvolvimento

http://www.proifes.org.br/noticias-proifes/secretaria-do-mec-defende-cobranca-de-mensalidades. Acesso em março de 2017. 
nacional, regional ou local; de promover a articulação integrada da formação profissional com entidades demandantes de naturezas diversas, visando melhorar a eficácia e a eficiência das organizações públicas e privadas por meio da solução de problemas e geração e aplicação de processos de inovação apropriados; além de contribuir para agregar competitividade e aumentar a produtividade em empresas, organizações públicas e privadas. (DOU de 24/03/2017.grifos nossos) ${ }^{9}$

Fica evidente que a política universitária atualmente em vigor, apesar de não explicitada, é a de treinamento de interesse específico para o mercado, diferente da que consta na PNPG que explicitava a ciência e a tecnologia como de interesse nacional. Com estas medidas se ampliam o ensino e a pesquisa como mercadorias para atender a especificidades do mercado.

Em São Paulo, o estado mais rico da nação, que conta com a FAPESP - Fundação de Amparo à Pesquisa do Estado de São Paulo, o governador disse que a instituição deveria financiar pesquisas utilitárias. O que é utilidade? Segundo o governador, a FAPESP gasta dinheiro com pesquisas acadêmicas sem nenhuma utilidade prática para a sociedade, porém apenas $10 \%$ do financiamento da FAPESP foi para a área de ciências humanas e sociais ${ }^{10}$. A destinação de recursos para as áreas de interesse empresarial, porém, não cessam de expandir. A FAPESP informa que um número recorde de 45 startups foram selecionados para receberem recursos do PIPE - Pesquisa Inovativa em Pequenas Empresas ${ }^{11}$, além de outros 42 com recursos da FAPESP e FINEP - Financiadora de Estudos e Projetos, para atender a demanda de setores estratégicos, como Cidades Inteligentes, aplicações espaciais, instrumentação para o novo acelerador Sirius e para buscar soluções inovativas para o combate ao vírus Zika e seu vetor, o Aedes aegypti, totalizando 87 projetos que receberam recursos ${ }^{12}$. Sem desmerecer a importância dos financiamentos e da função e papel do Estado no financiamento, sinalizamos a direção dos recursos públicos para determinadas áreas. São questões não dissociadas que revelam o que a atual política pretende.

Para manter a estrutura funcionando se justifica contenções de recursos, repressão aos que pensam diferente, bombas e armas contra os estudantes, ou seja, não para pensar mas para deter o pensamento crítico ou contrário ao poder. E o que dizer do projeto de escola sem partido que quer dizer na realidade a escola sem pensamento crítico? Volta-se ao tempo do decoreba em geografia. Afinal se não podemos pensar a realidade para que

Diário Oficial da União de 24 de março de 2017.

10 http://www1.folha.uol.com.br/ciencia/2016/04/1765028-alckmin-critica-fapesp-por-pesquisas-sem-utilidade-pratica.shtml - acesso em março de 2017.

${ }_{11}$ De acordo com a FAPESP todas as empresas apoiadas pelo PIPE têm até 250 empregados. Não exige que os proponentes tenham titulação formal de graduação ou pós-graduação, se comprovarem ter conhecimento e competência técnica nas áreas relacionadas ao projeto, ou seja, aplica-se o notório saber.

12 http://agencia.fapesp.br/fapesp_e_finep_ampliam_apoio_a_inovacao_empresarial/25141/. Acesso em março de 2017 
serviria a universidade e a pós-graduação? Dar o título de doutores para que possam servir ao "mercado"? Mercado é uma abstração, mas nas justificativas fica evidente que é uma forma de privatizar a universidade e montar cursos que servem ao capital.

O gigantesco corte orçamentário de 44\% na ciência brasileira, anunciado no dia 30 de março de 2017, repercute no exterior ${ }^{13}$ e deixa horrorizados os cientistas brasileiros, o que explica a movimentação das entidades de pesquisa, como dito anteriormente.

À relação entre a política para a educação superior de forma direta é fundamental acrescentar a forma indireta que repercutirá na produção científica, tal como o corte de recursos decorrente da aprovação da PEC 55 que define a contenção de despesas em educação, saúde e assistência social por 20 anos. A contenção significa o fim da ampliação das universidades e dos cursos de pós-graduação, diminuição de bolsas de estudo, restrição de recursos para encontros e para publicações.

Recursos também vão escassear decorrentes da aprovação da Lei n ${ }^{\circ}$ 13.365/2016 que acabou com sistema de partilha do pré-sal, voltando-se para o regime de concessão. Sem analisar aqui o significado desse retorno ao passado, que implica entregar a exploração de uma riqueza esgotável às corporações internacionais (tema para muitos estudos e pesquisas), detenho-me no fato de que os royalties de $75 \%$ para educação e de $25 \%$ para a saúde no regime de partilha do pré-sal não mais ocorreram no sistema de concessão.

Adicione-se ao corte de 44\% no orçamento da pesquisa para 2017, os 20 anos de contenção de despesas, os royalties do pré-sal que vão deixar de ir para a educação, a extinção do Ministério de Ciência e Tecnologia e de sua junção com o Ministério das Comunicações e se tem uma ideia de como a política de educação superior mudou de sentido e de significado quando comparado ao período imediatamente anterior.

O PNPG destacava como prioridades e áreas estratégicas para a pesquisa: a saúde pública, o desafio urbano, o ensino médio e a educação básica, a política nuclear, os problemas ligados ao clima, à energia, ao pré-sal e às questões sociais pertinentes. Hoje apenas se fala em contas, em profissionais para atender ao mercado sem levar em consideração um projeto de desenvolvimento e o conteúdo da pesquisa científica.

Como atentar para o ensino médio e a educação básica quando foi sancionada, sem debate com a sociedade, a Lei $\mathrm{n}^{\circ} 13.415 / 2017$ da reforma do ensino, totalmente contrária ao que propugnava o PNPG, que destacava a necessidade de desenvolver estudos relativos à formação de professores, ao estabelecimento dos padrões mínimos de qualidade, à gestão

${ }_{13}$ https://falandoverdades.com.br/2017/04/05/principal-revista-cientifica-do-mundo-diz-que-temer-e-psdb-destruiram-ciencia-brasileira/ 
das escolas e à adequação dos currículos tendo em vista as necessidades e os interesses dos adolescentes e jovens currículos tendo em vista as necessidades e os interesses dos adolescentes e jovens sujeitos da educação Básica, notadamente do ensino médio?

O que se foi aprovado demonstra a ideia de uma formação tecnicista e limitante para pensar a sociedade e o ensino de Geografia. Os estudos sobre, por exemplo, o ensino da Geografia o que ocorrerá com eles? E isto sem falar no tal de “notório saber”. E a Geografia como será no ensino médio? Terá Geografia? Lembro que quando a ditadura impôs os estudos sociais a academia, a AGB (a ANPEGE ainda não existia porque os cursos de pós eram muito limitados) se posicionou e conseguiu reverter os estudos sociais para as matérias específicas.

No momento em que, cada dia sofremos um arrastão diário que até nos impede de darmos conta de analisar em profundidade, ou, às vezes, até damos conta, mas não temos fôlego para compreender o significado de todas as transformações. Ou apenas se naturaliza sem compreender que aparentemente pequenas alterações implicam na totalidade da pósgraduação em Geografia?

E as universidades estaduais e municipais? Os deputados poderão analisar em breve o Projeto de Lei Complementar - PLC n³ 343/17, do Executivo, que cria o Regime de Recuperação Fiscal dos Estados e do Distrito Federal, a fim de ajudar os entes endividados, em troca de contrapartidas como elevação de alíquotas de contribuição social de servidores, redução de incentivos tributários e privatizações. Na proposta, o regime poderá durar até três anos, com prorrogação pelo mesmo período inicial. Durante esse prazo inicial estipulado em lei, o estado não pagará as prestações da dívida devidas à União. Os valores não pagos serão corrigidos pelos encargos financeiros previstos originariamente nos contratos para acrescentálos aos saldos devedores atualizados. Além de medidas de redução de gastos, que cada ente federado participante deverá instituir por meio de leis próprias, a moratória provisória será garantida pela vinculação de recursos dos repasses aos estados previstos constitucionalmente (IRRF descontado de seus servidores, Fundo de Participação dos Estados, parte do IPI), e de tributos de sua competência (IPVA, ICMS, transmissão causa mortis). O que ocorrerá com as universidades estaduais e municipais se a PLC n.343/17 for aprovada?

O que significa a reforma da previdência para os professores na ativa, para os que vão entrar e para os que não vão? Não vão porque o tempo de permanência na ativa é expandido e, além disso, não há previsão da expansão de universidades. E se os professores universitários demorarem muito tempo para se aposentar, com a política de contenção de 20 anos não haverá novas vagas e nem novas ideias, haverá retração de vagas que implica 
em mais permanências e retrocessos do que mudanças. A atual política é de contenção, sem criação e sem expansão das universidades, os mestrandos e doutorandos terão que esperar mais tempo para entrar como professores nas universidades. È a precariedade imposta para dar fim ao pensamento critico. Assim o pensamento único domina cada vez mais.

Outro aspecto do financiamento público de estudos e pesquisas são os que foram realizados para analisar, por exemplo: as políticas metropolitanas, as cidades médias, a implantação de planos diretores, a produção do Programa Minha Casa Minha Vida, a regularização fundiária, etc. Uma política para a educação superior que inclui a academia analisando os programas governamentais é fundamental, o que levou a fazer com que parte das pesquisas fosse centrada na agenda governamental. (RODRIGUES, 2016).

Dentre as limitações, que não aparecem como política para a educação superior mas que interfere no conhecimento, está o corte de questões a serem apuradas no recenseamento de Censo Agropecuário com a "desculpa" de falta de recursos.

No urbano e rural estamos às voltas com a Medida Provisória - MP 759 que estrangula a reforma agrária e a reforma urbana e fragilizam a conquista da função social da propriedade, além de tantas outras MP, decretos, projeto de leis etc. Há um torvelinho de alterações que é importante refletirmos para não naturalizar as alterações como se fossem apenas de forma e acreditando que tudo vai passar. E que ao que tudo indica a academia, pelo menos no que tenho observado na Geografia, aceita imposições com poucas análises críticas mais gerais.

Em síntese a política para a Educação Superior está em crise. Reduziu-se o tempo para a pesquisa e a reflexão, ampliam a pós-profissional para o doutorado, propõe-se cobrança para os mestrandos e doutorados científicos das universidades públicas, restringem-se recursos para a pós, limita-se a pesquisa, retira-se recursos públicos, exige-se publicação de alunos e professores em revistas especializadas, participação em congressos etc. A universidade não terá mais produção cientifica, apenas produtivismo calcado no Google - uma empresa privada. Temos que nos movimentar em conjunto para difundir o pensamento critico antes que o pensamento único não deixe brechas para a criatividade.

Penso que a proposta da ANPEGE que nos convidou para fazer a exposição é de que nos movimentemos no sentido de compreender as transformações. Em linguagem poética, Rosa de Luxemburgo disse que quem não se movimenta não percebe as correntes que o aprisionam. A proposta é, portanto, nos movimentarmos, refletirmos e nos posicionarmos com o objetivo de termos uma Geografia que pense a realidade e que nela possa intervir. 


\section{Referências}

1. AGAMBEN, Giorgio. La Potencia del Pensamento. Barcelona. Editorial Anagrama, 2008.

2. MAZZUCATO, Mariana. O Estado Empreendedor. Desmascarando o mito do setor público vs Setor privado. São Paulo : Portfolio-Pequim, 2014

3. OLIVEIRA, Márcio Piñon e SANT'ANNA NETO, João Lima (2014).Disponível em http://anpege. org.br/revista/ojs-2.4.6/index.php/anpege08/article/view/413/198. < Acesso em março de 2017>.

4. RODRIGUES, Arlete Moyses. Ponderações sobre ausências e presenças em estudos de Geografia Urbana. In SPÓSITO, Eliseu Savério; SILVA, Charlei Aparecido da Silva; SANTÁNNA NETO, João Lima; MELLAZZO, Everaldo Santos. A diversidade da Geografia Brasileira. Rio de Janeiro : Consequencia, 2016.

ARTIGO RECEBIDO EM MAIO DE 2017.

ARTIGO APROVADO EM JULHO DE 2017. 